\title{
POTENCIALIDADES DE UM ARQUIVO ESCOLAR: O CASO DO NÚCLEO DE DOCUMENTAÇÃO E MEMÓRIA DO COLÉGIO PEDRO II
}

Tatyana Marques de Macedo Cardoso Universidade Federal Fluminense tatyana_marques@yahoo.com.br

Claudia Maria Costa Alves de Oliveira Universidade Federal Fluminense cmcalves@yahoo.com

\section{RESUMO}

O presente trabalho tem como objetivo apresentar o potencial histórico arquivístico do Núcleo de Documentação e Memória do Colégio Pedro II (NUDOM) para as pesquisas acadêmicas a partir do seu vasto acervo. Essa instituição secular de ensino, criada em 1837, localizada no Centro do Rio de Janeiro, se constitui em um "lugar de memória", personagem/objeto, patrimônio da História da Educação Brasileira. O acervo documental deste Núcleo tem valor inestimável para a instituição e alto grau de relevância para a pesquisa, pois dimensiona a importância do Colégio no desenvolvimento da Educação Brasileira.

Palavras-chave: Colégio Pedro II. Núcleo de Documentação e Memória. Arquivo escolar.

\section{POTENTIALITIES OF A SCHOOL ARQUIVE: THE CASE OF THE DOCUMENTATION AND MEMORY NUCLEUS OF THE PEDRO II SCHOOL}

\begin{abstract}
This paper aims to present the historical archival potential of the Documentation and Memory Nucleus of the Pedro II School (NUDOM) for academic research from its vast collection. This secular institution of teaching, created in 1837, located in the Center of Rio de Janeiro, constitutes a "place of memory", character / object, heritage of the History of Brazilian Education. The documentary collection of this Nucleus has invaluable value for the institution and a high degree of relevance for the research, since it dimension the importance of the School in the development of the Brazilian Education.
\end{abstract}

Keywords: Pedro II School. Documentation and Memory Nucleus. School arquive.

\section{POTENCIALIDADES DE UN ARCHIVO ESCOLAR: EL CASO DEL NÚCLEO DE DOCUMENTACIÓN Y MEMORIA DEL COLEGIO PEDRO II}

\section{RESUMEN}

El presente trabajo tiene como objetivo presentar el potencial histórico archivístico del Núcleo de Documentación y Memoria del Colegio Pedro II (NUDOM) para las investigaciones académicas a partir de su vasto acervo. Esta institución secular de enseñanza, creada en 1837 , en el Centro de Río de Janeiro, se constituye en un "lugar de memoria", personaje / objeto, patrimonio de la Historia de la Educación Brasileña. El acervo documental de este Núcleo tiene valor inestimable para la institución y alto grado de relevancia para la investigación, pues dimensiona la importancia del Colegio en el desarrollo de la Educación Brasileña. 
Palabras clave: Colegio Pedro II. Núcleo de Documentación y Memoria. Archivo escolar.

\section{LE POTENTIEL D'UN FICHIER DE L'ÉCOLE: LE CAS DU NOYAU DE LA DOCUMENTATION ET DE LA MÉMOIRE DU COLLÈGE PEDRO II}

\section{RÉSUMÉ}

Cet article a pour but de présenter le potentiel archivistique historique du Noyau de Documentation et de Mémoire du Collège Pedro II (NUDOM) pour la recherche académique à partir de sa vaste collection. Cette institution laïque d'enseignement, créée en 1837, située dans le Centre de Rio de Janeiro, constitue un "lieu de mémoire", personnage / objet, patrimoine de l'histoire de l'éducation brésilienne. La collection documentaire de ce noyau a une valeur inestimable pour l'institution et un haut degré de pertinence pour la recherche, puisqu'elle souligne l'importance du Collège dans le développement de l'Éducation Brésilienne.

Mots-clés: Collège Pedro II. Noyau de Documentation et de Mémoire. Archives de l'école.

\section{INTRODUÇÃO}

O presente trabalho tem como objetivo apresentar o potencial histórico arquivístico do Núcleo de Documentação e Memória do Colégio Pedro II (NUDOM) para as pesquisas acadêmicas. Essa instituição secular de ensino, criada em 1837, localizada no Centro do Rio de Janeiro, constitui-se em um "lugar de memória", personagem/objeto, patrimônio da História da Educação Brasileira.

O Núcleo de Documentação e Memória, criado em 1995, é um centro de documentação especializado no tratamento, preservação e divulgação das obras do seu acervo documental. Configura-se como um laboratório de pesquisa, tornando-se um espaço de fundamental importância para os pesquisadores da História da Educação no Brasil. Os fatos históricos que marcaram a vida do Colégio Pedro II e, por conseguinte, do país encontram-se registrados no acervo do NUDOM. Importante destacar que essa Instituição, primeira escola de ensino secundário do Brasil, completa neste ano de 2017, 180 anos de existência.

O NUDOM abriga um acervo único, composto de aproximadamente 18.000 itens, organizado e disponível para a sua comunidade escolar e, também, para o público externo. No intuito de organizar esse "pequeno grande tesouro" da História da Educação Brasileira, tornase imprescindível a atuação de profissionais especialistas, tais como bibliotecários e historiadores. Através da catalogação, classificação e indexação dos documentos é possível recuperar e dar acesso à documentação sob sua guarda. 
Os arquivos, bibliotecas e centros de documentação, na sua concepção de difundir a memória através dos seus documentos, configuram-se como um "lugar de memória" (NORA, 1993) para os pesquisadores a fim de realizarem suas pesquisas históricas e, por conseguinte, gerar conhecimento através da socialização da informação. Nessa perspectiva, Barros e Neves (2009, p. 59) asseguram que o arquivo como lugar de "construção do saber é o mediador que permite o acesso do pesquisador ao objeto da pesquisa ampliando, dessa forma, as possibilidades de avanço para o exercício da produção do conhecimento".

Inúmeras temáticas e diferentes objetos de estudo vêm sendo desenvolvidos no interior do Núcleo de Documentação e Memória do Colégio Pedro II, ganhando destaque nas pesquisas acadêmicas, principalmente no campo da História da Educação, seus arquivos e fontes. Vários aspectos podem ser abordados no interior dessa instituição escolar, tais como: o contexto histórico e as circunstâncias específicas da criação e da instalação da escola; seu processo evolutivo: origens, apogeu e situação atual; o cotidiano da escola; o edifício escolar: organização do espaço, estilo, acabamento, implantação, reformas e eventuais descaracterizações; os alunos: origem social, destino profissional e suas organizações; os professores e administradores: origem, formação, atuação e organização; os saberes: currículo, disciplinas. Seus livros, arquivos e fontes primárias ganharam espaço na forma de praticar e escrever a História da Educação.

Compreende-se a escola como uma instituição que faz parte da história da sociedade e seu acervo constitui um caminho tanto para a mantença da memória institucional quanto para a pesquisa dos vestígios relativos às práticas administrativas e pedagógicas dos diferentes sujeitos educativos.

Assim, cabe aqui ressaltar a importância dos arquivos escolares como espaços de pesquisa para a História da Educação. A partir de seus acervos, há variadas possibilidades de construção de objetos de pesquisa que podem contribuir para se resgatar o protagonismo dos sujeitos na história, ampliando a compreensão sobre os processos de escolarização.

\section{OS PESQUISADORES E OS DOCUMENTOS}

Os pesquisadores têm se lançado na tarefa de construir estudos históricos em diversas áreas, notadamente, no campo da História da Educação. Apesar da importância dos documentos para o conhecimento do patrimônio cultural e histórico, os pesquisadores ainda se deparam e lidam com muitas dificuldades para desenvolver suas pesquisas históricas. Embora já venha ocorrendo uma discussão em torno das questões que norteiam a preservação do 
patrimônio documental, ainda assim, existem poucas iniciativas concretas. A ideia de que os arquivos públicos representam "lugares da memória", posta no século XIX, ainda não chegou às escolas, uma vez que essas instituições ainda estão pouco atentas à historicidade de suas práticas. Mas, apesar das dificuldades encontradas com relação à documentação escolar, algumas instituições vêm se preocupando em preservar a sua documentação. É o caso do Colégio Pedro II através do seu Núcleo de Documentação e Memória (NUDOM).

$\mathrm{Na}$ tarefa de construir seus estudos históricos, pesquisadores de diversas áreas do conhecimento vão ao NUDOM para iniciar suas investigações, deparando-se com documentos variados. "Se o documento é o ponto de partida para se conhecer um fato histórico é, também, através dele que podemos revisitar o passado e reinterpretá-lo sob nova ótica" (FÁVERO, 2000, p. 103). Os documentos históricos que compõem o acervo do Núcleo de Documentação e Memória descrevem o resultado das atividades desta entidade no cumprimento de seus objetivos e finalidades. Como afirmam Nunes e Carvalho (2005, p. 33), "a palavra documento vem do latim documentum, derivado de docere, 'ensinar', e que evoluiu para o significado de 'prova'. O uso do termo no vocabulário legislativo foi difundido no século XVII. O seu sentido moderno de testemunho histórico data apenas do início do século XIX”.

O termo documento foi evoluindo no decorrer do tempo, apresentando o significado de prova e testemunho. Dessa forma, começava a apresentar relevância para a história, pois, se os acontecimentos não fossem registrados, havia o risco de se perderem no tempo. $\mathrm{O}$ valor informacional dos documentos - como prova e testemunho - serve à reconstrução histórica e à sociedade.

A história não poderia ser escrita se não existisse um conjunto de provas e testemunhos em que os documentos, sem dúvida alguma, ocupam um lugar importante para a instituição, e, sobretudo, para a sociedade que os utiliza como fins de pesquisa. Os documentos são essenciais e constituem, sem dúvida, matéria-prima para o pesquisador. Nesse sentido, o papel do pesquisador é ver o passado através dos olhos do presente e à luz de suas questões.

"No trabalho com as fontes, aprendemos que, quando penetramos num arquivo, dialogamos com os documentos, procurando compreender o não dito ou aquilo que foi esquecido ou silenciado" (FÁVERO, 2000, p. 105). Há uma sensação de descoberta e de fascínio durante o contato com as fontes de pesquisa. Assim, faz-se necessária a organização dos acervos escolares, através dos seus arquivos e coleções, a fim de disseminar o patrimônio da instituição, criando condições que garantam a preservação e o acesso às informações contidas nesses documentos. 
Os arquivos escolares são, sem dúvida, valiosos tesouros para os pesquisadores no âmbito da História da Educação e neles estão contidos diversos tipos de documentos e registros, exigidos pela administração e pelo cotidiano burocrático, que perpassam inclusive seu âmbito pedagógico. Há toda uma legislação que orienta essa produção, envolvendo o funcionamento da instituição e a organização e o controle de suas atividades. Além disso, pode-se encontrar no arquivo escolar outros tipos de documentos que excedem a determinação legal, como fotografias, jornais produzidos pela escola, cadernos de alunos, recortes de jornais com matérias referentes à instituição, bilhetes entre outros.

Tendo sido produzidos com maior ou menor intencionalidade, tais documentos registram e compõem a cultura material escolar, específica daquela instituição. Ou seja, são testemunhos da vida institucional, da sua cultura e da memória, com as particularidades da escola que os produziu. Embora saibamos de sua relevância e de seu grande potencial para as pesquisas, muitas escolas ainda não se preocupam em preservar a riqueza do material encontrado em seus arquivos. Diante de tais circunstâncias, muitas delas motivam profundas preocupações relativas à salvaguarda e preservação dos seus documentos, pois, na maior parte dos prédios escolares, até hoje, os documentos estão abrigados e guardados em porões úmidos ou salas apertadas, correndo os riscos da efemeridade. Tendo em vista tais riscos, é fundamental refletirmos sobre as ações que devem ser estabelecidas em prol da preservação da memória, e, consequentemente, do direito a ela, pois o passado pode ser fonte de pesquisa e, portanto, revisitado.

Sendo assim, cabe-nos uma questão: como podemos garantir o direito à memória e, consequentemente, a preservação de fontes documentais e de acervos de memória de instituições escolares?

A preservação dessas fontes e da memória que elas representam, sobre um passado de escolarização, com características próprias da instituição escolar aos quais pertencem, ainda é uma questão de pouca importância na sociedade brasileira. Dessa maneira, as escolas sofrem com o abandono de sua documentação, seja pela falta de interesse das instituições envolvidas, pela ausência de políticas institucionais de preservação e pelo descaso com a memória e a cultura em nosso país.

Temos que enfrentar esses desafios e chamar a atenção dos poderes públicos e dos pesquisadores, em geral, para a importância da preservação de fontes documentais e de acervos de memória. Como lugares de memória, locais de guarda dos acervos, os arquivos escolares devem estar constantemente abertos a novas leituras acerca do passado e presente. 
De acordo com Mogarro (2006), a relevância dos arquivos configura-se pelo fato de ser um espaço onde foi deixado, ao longo do tempo, documentos e testemunhos, que possibilitam o conhecimento, a apreensão da vida das instituições.

A importância do lugar do arquivo na instituição escolar tem acompanhado a afirmação dessa mesma instituição como um microcosmos com formas e modos específicos de organização e funcionamento. As escolas são estruturas complexas, universos específicos, onde se condensam muitas das características e contradições do sistema educativo. Simultaneamente, apresentam uma identidade própria, carregada de historicidade, sendo possível construir, sistematizar e reescrever o itinerário de vida de uma instituição (e das pessoas a ela ligadas), na sua multidimensionalidade, assumindo o seu arquivo um papel fundamental na construção da memória escolar e da identidade histórica de uma escola. (MOGARRO, 2006, p. 73).

$\mathrm{Na}$ perspectiva de sua utilização como fonte de pesquisa e de ensino para a compreensão da história da instituição escolar, o arquivo deixa de ser algo relegado ao esquecimento, a depósitos insalubres ou mesmo de ser entendido como algo descartável, indesejado e inútil. Essa pode ser uma possibilidade muito promissora para uma desejável articulação entre ensino e pesquisa e também para a promoção de diálogos com a comunidade escolar, por meio de diferentes atividades e projetos que envolvam um novo olhar para os arquivos escolares.

\section{O COLÉGIO PEDRO II}

A criação do Colégio Pedro II (CPII) deve-se à inspiração do ministro do Império, Bernardo Pereira de Vasconcellos, durante a regência de Araújo Lima, logo após a independência do Brasil. O momento histórico era de consolidação da monarquia, e os governantes preocupavam-se com a construção de um sentimento de nação, ou melhor, de uma identidade nacional pela educação e pela cultura. Ao criar o Colégio Pedro II, o ministro Bernardo Pereira de Vasconcellos tomou como modelo os liceus franceses idealizados por Napoleão Bonaparte, como, por exemplo, o Colégio Henrique IV e Luís, O Grande.

O Colégio Pedro II tornou-se, assim, a primeira Escola de Ensino Secundário no Brasil, criado em 1837, para atender às necessidades de formação de uma elite social que ocuparia os principais cargos da administração pública e do governo.

A instituição de ensino representou um lócus de formação tanto do currículo quanto do ensino das diferentes disciplinas escolares que compõem a grade curricular das escolas brasileiras até os dias de hoje. O modelo de ensino implementado no Colégio, caracterizado por estudos simultâneos, sequenciais e seriados, iniciou o processo de consolidação dos 
programas curriculares e materiais didáticos e permitiu a construção teórico-metodológica de várias disciplinas escolares, fornecendo-nos, assim, materiais sobre as disciplinas ensinadas no Brasil. Essa organização pedagógica pode ser constatada por meio do Mapa das Lições ${ }^{1}$, que continha a grade curricular idealizada para os primeiros anos do curso, indicando as diferentes matérias escolares e o número de tempos semanais atribuídos a cada uma delas, além de apresentar os conteúdos fundamentais dos Programas de Ensino, como também a indicação dos manuais didáticos que seriam adotados para os alunos.

As disciplinas ou - como se dizia no século XIX - as "cadeiras" que compunham os programas de ensino do Colégio Pedro II eram estabelecidas pelo Governo Imperial, em consonância com as propostas que fundamentavam o projeto civilizatório do Estado de formar uma elite capacitada a gerir a construção da nação que se objetivava concretizar. Apesar disso, o conteúdo das disciplinas estava a cargo dos catedráticos - professores do Colégio responsáveis pelas cadeiras - em sua maioria, autores dos livros didáticos ali adotados. Esses catedráticos formavam uma categoria de professores autores, intelectuais que possuíam um status acadêmico equiparado aos catedráticos do ensino superior, muitas vezes sendo eles mesmos os integrantes das cátedras nos dois níveis de ensino.

Os catedráticos, além de escrever os compêndios usados pelos alunos, elaboravam o Programa de Ensino e tomavam parte das principais decisões políticas e pedagógicas do Colégio $^{2}$ na Congregação. Importante destacar que os Programas de Ensino do Colégio Pedro II representam fontes de valor inestimável para a compreensão do processo de disciplinarização de diferentes matérias escolares no Brasil e encontram-se disponíveis para pesquisa no NUDOM.

O ensino marcado pelo conteúdo enciclopédico e academicista, com o propósito de oferecer uma cultura geral ao aprendiz, constituía-se das chamadas "humanidades", disciplinas fundamentadas na cultura clássica como História, Geografia, Latim, Grego, Português e Literatura, Filosofia, Francês e Retórica que representavam mais de 50\% da carga horária das disciplinas.

As humanidades correspondiam a um modelo de formação que caracterizou a educação francesa por pelo menos quatro séculos. O estudo das humanidades revestia-se de

\footnotetext{
${ }^{1}$ O Mapa das Lições, parte integrante do Regulamento $n^{\circ}$ 8, primeiro regulamento do Colégio Pedro II, obra do Ministro Bernardo Pereira de Vasconcellos, datado de 31 de janeiro de 1838, que continha o primeiro estatuto do Colégio.

${ }^{2}$ Decreto $\mathrm{n}^{\circ} 8.227$, de 24 de agosto de 1881 . Art.2 ${ }^{\circ}$ Compete à Congregação: $1^{\circ}$ Organizar annualmente o programa do ensino e o horário das aulas e indicar as obras e compêndios que devam ser adoptadas nas mesmas aulas, submettendo tudo à aprovação do Ministro e Secretário de Estado dos Negócios do Império. (cf. ANNUARIO DO COLEGIO PEDRO II, nº I, 1914, p.88).
} 
um sentido cuja função achava-se além da instrução para incorporar um compromisso moral, promovendo a construção de valores que qualificariam o cidadão. Os conteúdos ensinados deveriam oferecer modelos de conduta, valorizando a figura do herói da Antiguidade, cuja virtude serviria de inspiração aos jovens aprendizes. Tratava-se de uma educação para formar o futuro cidadão, homem de bem, que iria desempenhar funções fundamentais para o Estado.

O Colégio projetou-se como personagem da História da Educação no Brasil através de seus professores-catedráticos, como por exemplo: Joaquim Manoel de Macedo, Antônio Gonçalves Dias, Capistrano de Abreu, Euclides da Cunha, Silvio Romero, João Ribeiro, Jonathas Serrano, José Veríssimo, Delgado de Carvalho, Pedro Calmon entre outros.

Teve alunos ilustres como: Joaquim Nabuco, Barão do Rio Branco, Visconde de Taunay, os presidentes Washington Luís, Rodrigues Alves e Hermes da Fonseca, Paulo de Frontin, Carlos de Laet, Jonathas Serrano, Antenor Nascentes, Manuel Bandeira, Afonso Arinos de Melo Franco, Fernando Segismundo, Pedro Nava, Alceu Amoroso Lima (Tristão de Athayde), Mário Lago, Gilberto Braga e outros mais.

Foram publicados livros didáticos de seus professores/autores de utilização nacional como: Lições de História do Brasil, de Joaquim Manuel de Macedo; História do Brasil, de João Ribeiro; Curso Elementar de Litteratura Nacional, de Joaquim Caetano Fernandes Pinheiro; Curso de Mathematica Elementar, de Euclides de Medeiros Guimarães Roxo; Methodo Pratico Para Aprender a Língua Francesa, de Gastão Ruch.

\section{O NÚCLEO DE DOCUMENTAÇÃO E MEMÓRIA DO COLÉGIO PEDRO II}

Foi criado há 22 anos, sendo, atualmente, parte integrante do Centro de Documentação e Memória do Colégio Pedro II, recém-criado através da Portaria n. 4231, de 4 de agosto de 2014. O Núcleo de Documentação e Memória (NUDOM) tem como principais objetivos resgatar e preservar a memória da educação dessa tradicional instituição de ensino, bem como estimular e implementar a realização de estudos e pesquisas em História da Educação.

Nessa perspectiva, a constituição de seu acervo privilegia documentos relacionados às práticas cotidianamente desenvolvidas na escola. Em razão de seus objetivos, o Núcleo de Documentação e Memória torna-se um laboratório de pesquisas, atendendo não só sua comunidade interna como também pesquisadores de diversas instituições de ensino do Brasil, da graduação à pós-graduação.

O NUDOM, como fonte essencial de pesquisa, destaca-se como um espaço capaz de “contar" inúmeras histórias através de seus documentos, objeto de construção histórica, 
possibilitando problematizar certas categorias sociais, determinados grupos e delinear a especificidade do objeto a ser pesquisado. O acervo documental deste Núcleo tem valor inestimável para a instituição e alto grau de relevância para a pesquisa, pois dimensiona a importância do Colégio no desenvolvimento da Educação Brasileira. É composto por um conjunto bibliográfico, arquivístico e iconográfico.

O acervo bibliográfico possui obras que datam dos primeiros anos da fundação do Colégio, representados por livros didáticos das disciplinas ministradas nos séculos XIX e XX; regulamentos, regimentos e relatórios desde 1838; programas de ensino desde 1856; coleção das leis do Brasil de 1808 a 1962; teses de concursos para a cátedra de 1878 a 1975; anuários elaborados pelo diretor-geral no exercício da função referente ao período de 1914 a 1961; monografias de conclusão de cursos de graduação e pós-graduação; teses de doutorado e dissertações de mestrado dos funcionários do Colégio Pedro II, incluindo os trabalhos realizados por pesquisadores externos que retratam a História da Educação tendo como fonte o Colégio e obras memorialísticas de professores e ex-alunos.

Figura 1 - Acervo Bibliográfico - NUDOM.

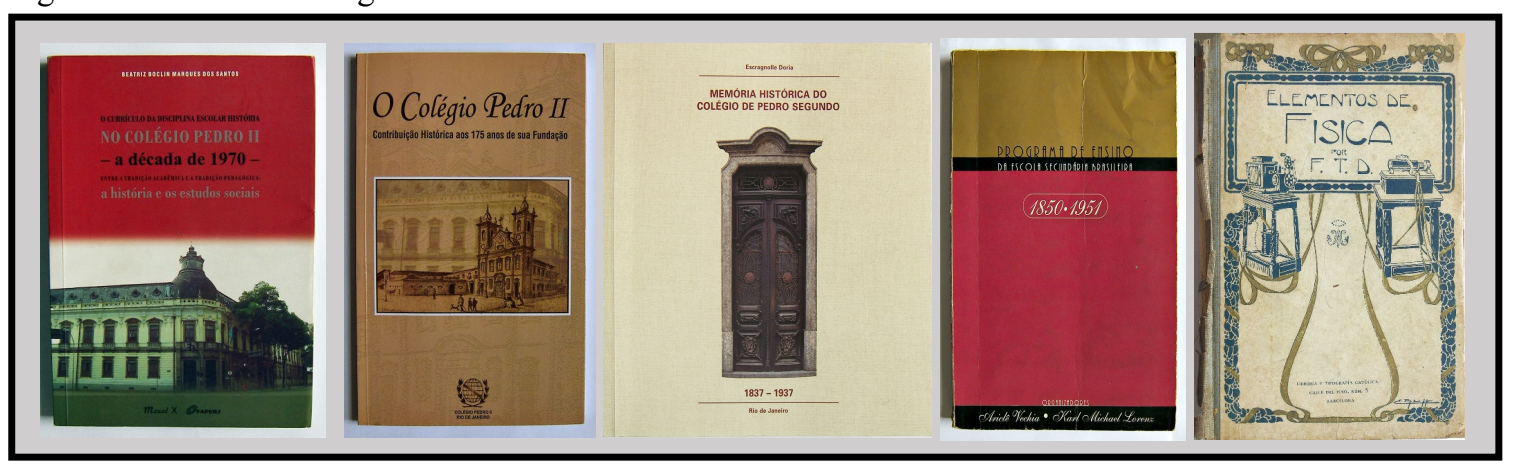

Fonte: Acervo do NUDOM - CPII.

O acervo arquivístico (acervo histórico ou fundo arquivístico) é a principal fonte de informação do NUDOM. Composto por um conjunto de obras manuscritas do século XIX e $\mathrm{XX}$, esse fundo remete às atividades de ensino e ao cotidiano da administração escolar. Está organizado em séries e subséries. Ou seja, cada coleção foi organizada de acordo com um significado próprio e cada item que a integra tem um significado individual a partir de um sentido coletivo, inerente ao conjunto a que pertence. É essa significação do conjunto que permite, a partir da pluralidade dos documentos aqui reunidos, a (re)construção de uma visão global da escola em diferentes épocas.

Destacam-se as seguintes obras: atas da Congregação; livros de atas de concursos de professores para ingresso no CPII; primeiro livro de avisos do Imperial Colégio de Pedro II de 
1838; livros de matrículas de alunos; livros de exames preparatórios; ofícios enviados e recebidos; avisos do Ministério do Império; livros de ocorrências disciplinares; livros de colação de grau e bancos de honra; livros de contabilidade; livros de nomeações de professores e funcionários; livros de médias e assentamentos escolares entre outros.

Figura 2 - Acervo Arquivístico - NUDOM.

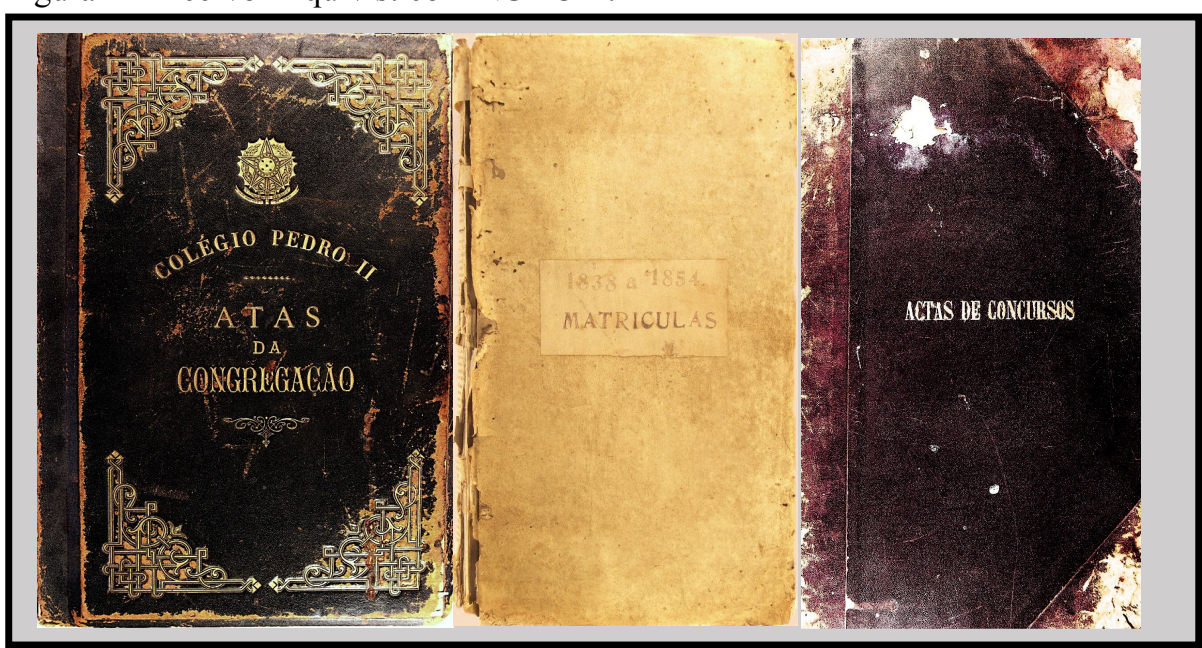

Fonte: Acervo do NUDOM - CPII.

O acervo iconográfico, composto por um conjunto de imagens referentes às cerimônias, festas, desfiles, concursos entre outras, constitui patrimônio imaterial ou intangível, uma vez que é percebido no conjunto de bens culturais simbólicos que compõem o espaço escolar. Esse tipo de patrimônio se define por práticas, representações, expressões, conhecimentos e técnicas. O conjunto de imagens salvaguardadas no NUDOM reúne o fazer cotidiano escolar, traz concepções de educação e expressa importantes fios constituintes de uma visão de mundo associada à escola. 
Figura 3 - Acervo iconográfico - NUDOM. Primeira turma mista, Rio de Janeiro, 1927.

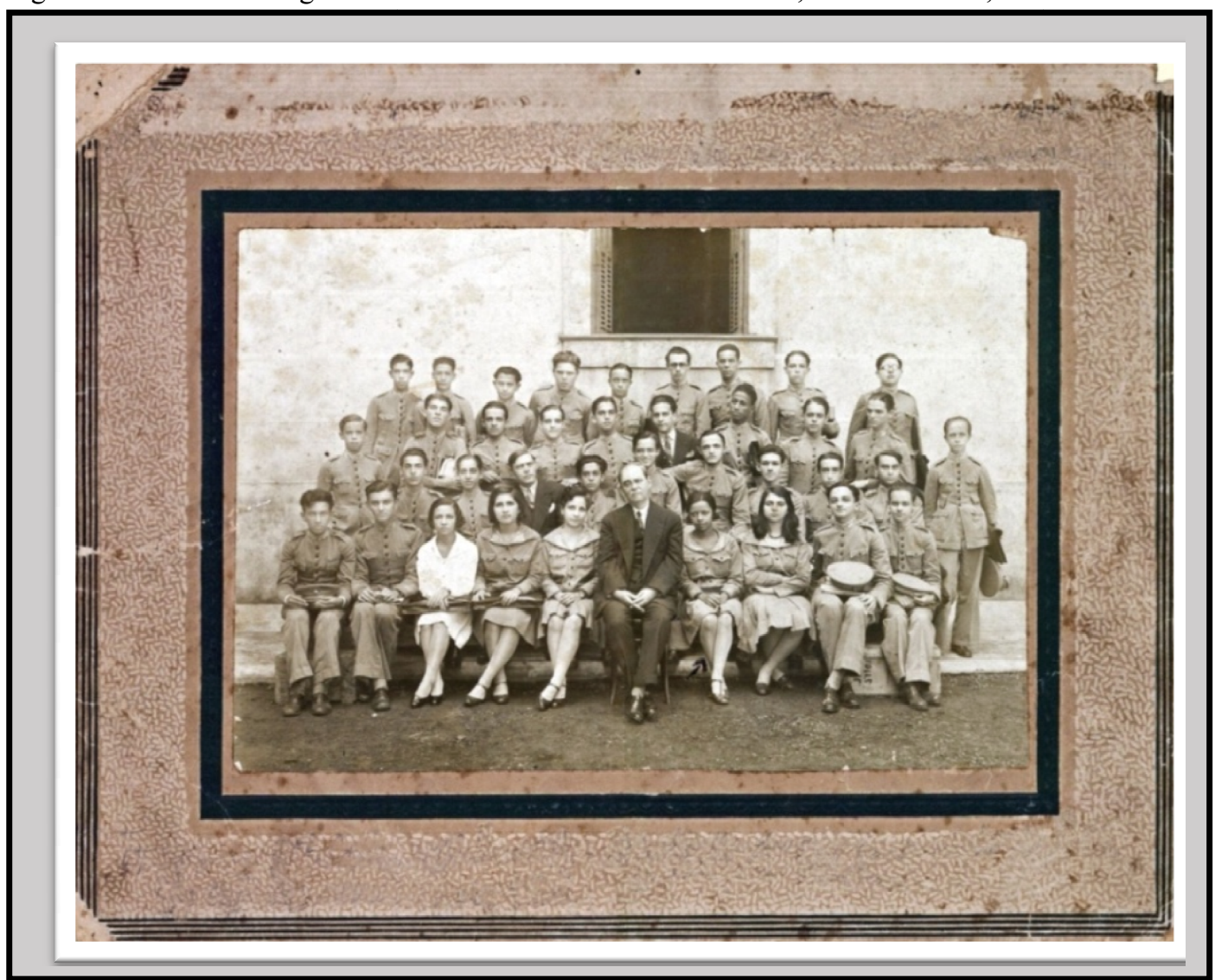

Fonte: Acervo do NUDOM - CPII.

Todo esse conjunto documental está organizado e disponível aos pesquisadores. Porém os mesmos precisam agendar a pesquisa via e-mail ou telefone antecipadamente, pois, há um limite de atendimento diário que se resume a três pesquisadores. Cabe ressaltar que por ser um acervo raro, único e especial, o NUDOM não realiza empréstimos, e o acesso às coleções é totalmente restrito aos funcionários. Fotos e cópias são permitidas, dependendo das coleções e das condições de preservação de cada documento.

Diante do exposto, o acervo do NUDOM apresenta uma gama de possibilidades de pesquisas acadêmicas, sobretudo, em História da Educação, através de suas fontes documentais. Livros, cadernos, objetos escolares, registros visuais, escritos, sejam sonoros ou iconográficos, que contam uma parte da história do Colégio Pedro II e da sua cultura material escolar no Rio de Janeiro, Brasil, desde as primeiras décadas do século XIX até meados da década de 1990, constituem grandes tesouros para os pesquisadores e estão reunidos no referido Núcleo. Esse acervo é composto por materiais variados relativos aos processos de escolarização, às práticas educativas lá criadas e vem merecendo investigações por parte de inúmeros pesquisadores de diferentes áreas do conhecimento. 
Com o compromisso de estimular estudos e pesquisas, abrindo caminhos à investigação, o NUDOM articula o trabalho de investigação com o de resgate, recuperação e organização de suas fontes documentais, democratizando, dessa maneira, o acesso à informação e valorizando o seu patrimônio cultural. Seus documentos, integrantes de vastos acervos, configuram possiblidades para a pesquisa e para a escrita da História da Educação.

\section{CONSIDERAÇÕES FINAIS}

Os acervos escolares escondem uma variada e valiosa quantidade de documentos que, muitas vezes, não são valorizados pela comunidade educacional nem pela sociedade. Esses documentos, se guardados e identificados, possibilitam desvendar o cotidiano da escola em diversas épocas, compreender seu funcionamento interno, a constituição do currículo e as práticas diárias de professores e alunos, sendo a chave capital para o estudo das instituições educacionais, sem abandonar outro tipo de documentação, consagrada e tradicional, como a legislação.

A preservação do patrimônio histórico educativo está intrinsecamente ligada ao conhecer, entender e divulgar a importância cultural e social da instituição escolar. A guarda e conservação da documentação escolar, fundamental para preservar a memória educativa, permite também valorizar os resquícios da construção da escola como espaço social peculiar da sociedade que a compõe e que se tornam, a cada dia, passíveis de esquecimento, abandono e, muitas vezes, descarte.

Numerosos documentos do Núcleo de Documentação e Memória do Colégio Pedro II "se hospedam em prateleiras e armários à espera de estudos e pesquisas. Portadores de discursos variados, alimentadores de imaginários, são fontes para o estudo da escola já que são elementos imprescindíveis na constituição de uma cultura escolar”. (CUNHA, 2012, p. 19).

A constituição e a manutenção de acervos escolares revestem-se de importância como forma de "atribuir novos significados às práticas escolares como elementos constitutivos da vida social [...], uma perspectiva que impõe aos pesquisadores o desafio de preservação das fontes históricas em arquivos públicos e a constituição de arquivos escolares" (MORAES; ALVES, 2000, p. 25). Sendo assim, o Núcleo de Documentação e Memória do Colégio Pedro II apresenta-se como um espaço importante dentro da referida instituição, guardião de fontes de informações fundamentais para a formulação de pesquisas, interpretações e análises sobre elas próprias, as quais permitem a compreensão do processo de ensino, da cultura escolar e, 
consequentemente, da História da Educação. Um "lugar de memória" capaz de fornecer elementos significativos para a reflexão sobre o passado da instituição, das pessoas que a frequentaram, das práticas educativas que lá circularam.

Por essas razões, ressaltamos a relevância das instituições escolares manterem seus arquivos e locais de guarda de documentos preservados e conservados, pois, esses documentos de origens diversas ocupam um lugar central e de referência no universo das fontes de informação que podem ser utilizadas para reconstruir o itinerário da instituição escolar.

Em linhas gerais, tais circunstâncias permitem evidenciar a importância que o Núcleo de Documentação e Memória do Colégio Pedro II tem no interior dessa instituição de ensino e para os pesquisadores, de maneira geral, nas pesquisas realizadas em História da Educação. Nele é possível encontrar documentos de diversos tipos e registros de caráter administrativo, pedagógico e histórico, documentos esses de valor inestimável, como: álbuns de fotografias, livros didáticos, relatórios, anuários, livros de matrículas de alunos, livros de nomeações de professores, trabalhos de alunos, cadernos de alunos entre outros, que permitem a compreensão do processo de ensino, da cultura escolar e, consequentemente, da História da Educação, tornando-se fontes de informações fundamentais e inéditas para a pesquisa.

\section{REFERÊNCIAS}

BARROS, Dirkene Santos; NEVES, Dulce Amélia de Brito. Arquivo e memória: uma relação indissociável. Revista TransInformação, Campinas, v. 21, n. 1, p. 55 -61, 2009.

CUNHA, Maria Teresa Santos. Rastros de Leituras: um estudo no acervo de livros do Museu da Escola Catarinense (décadas de 20 a 60 do século XX). Educação, Porto Alegre, v. 35, n. 1, p. 18-27, 2012.

FÁVERO, Maria de Lourdes de Albuquerque. Pesquisa, Memória e Documentação: desafios de novas tecnologias. In: FARIA FILHO, Luciano Mendes de (Org.). Arquivos, fontes e novas tecnologias. Campinas, SP: Autores Associados; Bragança Paulista, SP: Universidade São Francisco, 2000. p.101-116.

MORAES, Carmen Sylvia Vidigal; ALVES, Julia Falivene. Inventário de fontes documentais. São Paulo: Imprensa Oficial do Estado de São Paulo, 2000.

NORA, Pierre. Entre memória e história: a problemática dos lugares. Projeto História: Revista do Programa de Estudos Pós-Graduação em História e do Departamento de História da PUC-SP, n.10, p. 7-28, 1993. 
NUNES, Clarice; CARVALHO, Marta M. C. de. Historiografia da educação e fontes. In: GONDRA, José Gonçalves (Org.). Pesquisa em história da educação no Brasil. Rio de Janeiro: DP\&A, 2005. p. 17-62.

Recebido em: 30 de outubro de 2017 Aceito em: 07 de dezembro de 2017 